\title{
The many faces of demyelinating diseases: acute disseminated encephalomyelitis and Guillain-Barré syndrome in the same patient
}

As várias faces das doenças desmielinizantes: encefalomielite aguda disseminada e síndrome de Guillain-Barré no mesmo paciente

Régis Augusto Reis Trindade', Amália Izaura Nair Medeiros Klaes', Juliana Ávila Duarte²

Acute disseminated encephalomyelitis and Guillain-Barré syndrome represent distinct demyelinating diseases that share an autoimmune pathogenesis. A history of viral infection or vaccination are essential for the diagnosis ${ }^{1,2,3}$.

A 26-month-old boy presented with fever 10 days after vaccination (inactivated polio vaccine and tetravalent), progressive drowsiness, lower limb strength/sensory loss and urinary retention. The cerebrospinal fluid showed mild pleocytosis and an elevated total protein concentration; it was negative for infections. The initial MRI study was compatible with acute disseminated encephalomyelitis, with no spine abnormalities (Figure 1).

Ten days later, after therapy with corticosteroids, he experienced acute paraplegia. Follow-up brain and spine MRI scans demonstrated partial regression of brain lesions and nerve root thickening with intense enhancement extending along the cauda equina, compatible with Guillain-Barré syndrome. (Figure 2).
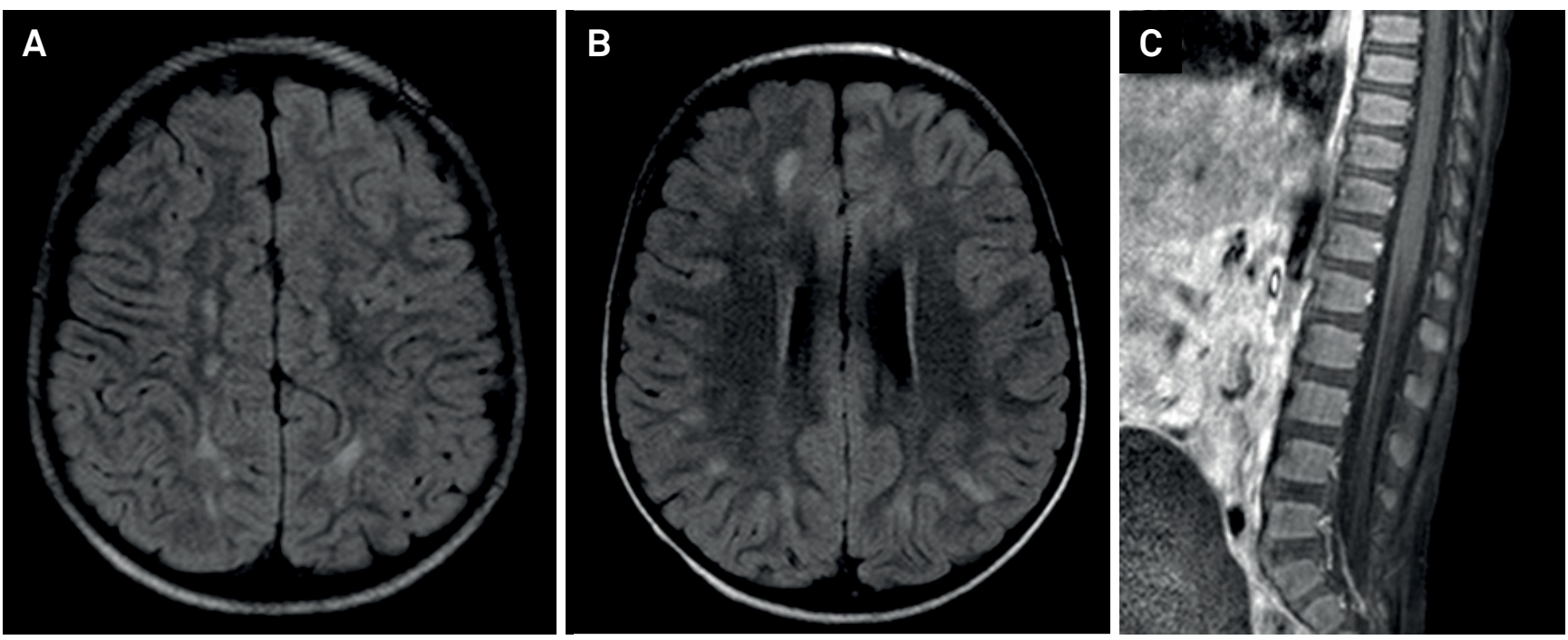

Figure 1. Brain MRI revealed white matter hyperintensities lesions in T2/fluid- attenuated inversion recovery (FLAIR) (A, B) in the cerebral hemispheres and cerebellum, without restriction to water molecules diffusivity or gadolinium enhancement, suggestive of acute disseminated encephalomyelitis. Sagittal T1 SPIR post-gadolinium (C), without cauda equina root enhancement.

\footnotetext{
${ }^{1}$ Hospital de Clínicas de Porto Alegre (HCPA), Radiologia e Diagnóstico por Imagem, Porto Alegre RS, Brasil;

${ }^{2}$ Hospital de Clínicas de Porto Alegre (HCPA), Ressonância Magnética, Porto Alegre RS, Brasil.

Correspondence: Régis Augusto Reis Trindade; R. Ramiro Barcelos, 2350; 90035-903 Porto Alegre RS, Brasil; E-mail: regis.artrin@gmail.com

Conflict of interest: There is no conflict of interest to declare.

Received 31 August 2016; Received in final form 29 December 2016; Accepted 03 February 2017.
} 

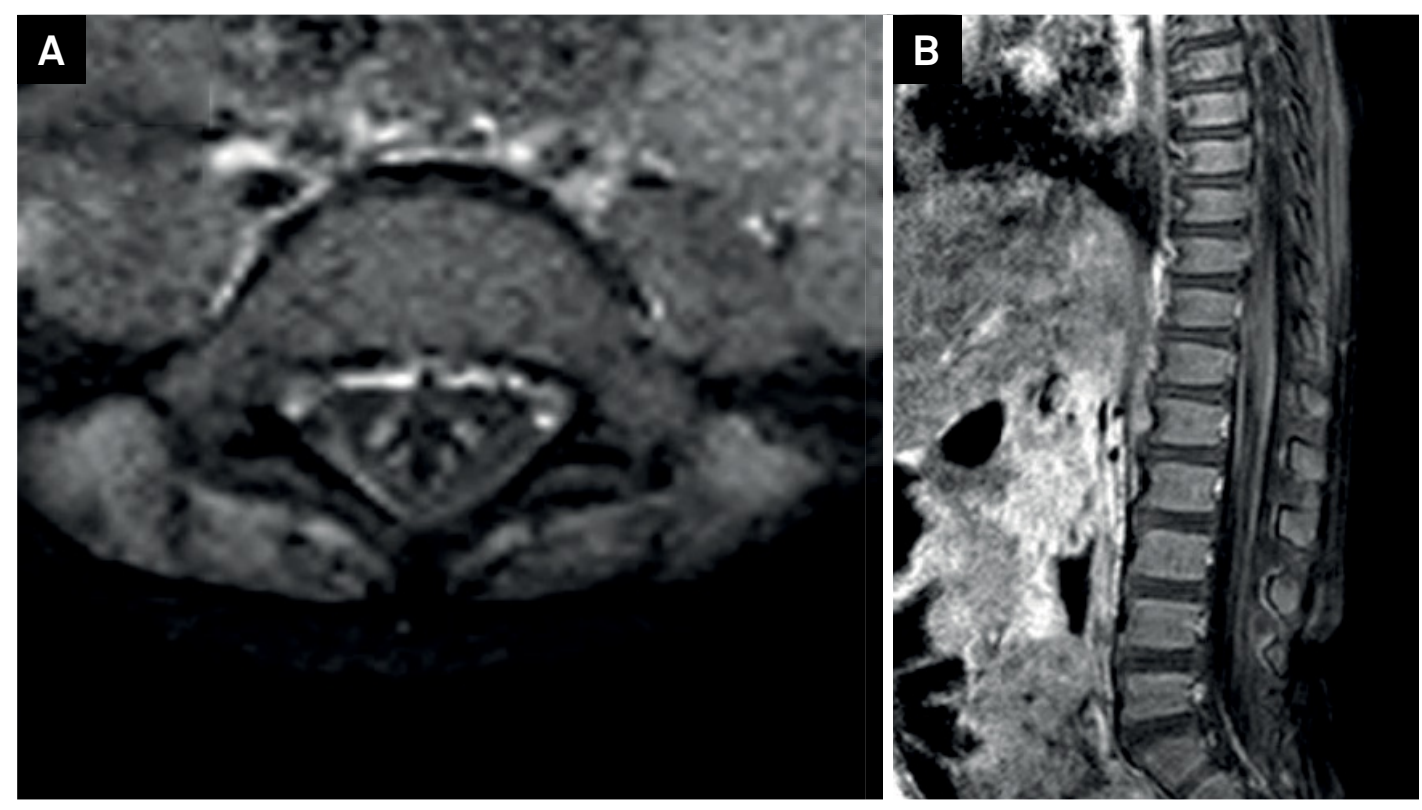

Figure 2. Follow-up MRI one week after steroids, showed partial recovery of the brain lesions; axial (A) and sagittal T1 SPIR post-gadolinium (B), enhancement of the cauda equina roots (white arrow), compatible with Guillain-Barré Syndrome.

\section{References}

1. Deshmukh IS, BangAB,Jain MA, Vilhekar KY.Concurrent acute disseminated encephalomyelitis and Guillain-Barré syndrome in a child.J Pediatr Neurosci 2015;10(1):61-3. https://doi.org/10.4103/1817-1745.154357

2. Okumura A, Ushida H, Maruyama K, Itomi K, Ishiguro Y, Takahashi M et al. Guillain-Barré syndrome associated with central nervous system lesions. Arch Dis Child. 2002:86(4):304-6. https://doi.org/10.1136/adc.86.4.304

3. Mohamed RR, Jan MM. Co-morbid Guillain-Barré syndrome and acute disseminated encephalomyelitis. Neurosciences (Riyadh). 2013;18(2):166-8 